\title{
Modification and avoidance of unmodifiable and unavoidable footshock
}

\author{
NANCY A. MARLIN, ALVIN M. BERK, and RALPH R. MILLER \\ Brooklyn College of the City University of New York, Brooklyn, New York 11210
}

\begin{abstract}
The majority of preference-for-signaled-shock experiments have been done using scrambled footshock. In the present study each of the 24 rats used as subjects was observed to modify the current density distribution or totally avoid scrambled footshock by making a postural adjustment during a signal preceding the shock. This suggests that footshock is inappropriate for investigating the preference-for-signaled-shock phenomenon due to the possibility of changes in the affective value of the shock through postural modification.
\end{abstract}

Preference for signaled shock (PSS) is the phenomenon in which subjects, given a choice between a signaled and unsignaled unmodifiable shock, prefer the signaled shock. The various hypotheses that have sought to elucidate the factors controlling this behavior include preparatory responding (Perkins, 1955; 1968), in which the signal allows the animal to "prepare" for the shock by emitting an internal response to attenuate the perceived aversiveness of the shock; signaled safety (Badia \& Culbertson, 1972; Lockard, 1963; Seligman, 1968), which permits phasic rather than chronic fear while in the apparatus; and a general information-seeking propensity of the organism (Berlyne, 1960). Underlying all of these theoretical analyses of PSS is the assumption that the shock is externally unmodifiable and unavoidable, such that the animal can emit no overt behavior to reduce or avoid the shock, or more precisely the affective value of the shock, in response to the signal.

Considerable discussion has been concerned with the proper methodology for delivery of such unmodifiable shock in PSS studies. Early studies reporting the effect were criticized for their use of unscrambled footshock, and indeed some researchers have attributed PSS solely to the overt modification an animal can make when the shock is preceded by a signal (Biederman \& Furedy, 1970). Such questions concerning the validity of PSS gave rise to studies using fixed electrodes such as ear clips (Perkins, Seymann, Levis, \& Spencer, 1966) and tail electrodes (Miller, Daniel, \& Berk, 1974; Miller, Marlin, \& Berk, 1977, Experiment 1). These studies obtained a robust PSS when no postural modification was possible. A similar finding has been reported for goldfish shocked in water (Fisher \& Badia, 1975), al-

This research was supported by National Science Foundation Grant BMS75-C 3383 and a grant from the City University of New York Faculty Research Award Program. R. R. M. is supported by National Institute of Mental Health Research Scientist Development Award MH-00061. The authors gratefully acknowledge John Sullivan, Michael Vigorito, and Silburn Thomas for their help in the data collection, and Joan Wessely for her assistance in preparing the manuscript. though problems such as variable total resistance due to changes in body orientation of the fish relative to the electrodes as it rotates in the plane perpendicular to the electrode plates, make this particular reported preference difficult to interpret.

Due to the relative difficulty of using fixed electrode preparations, the vast majority of the research concerning PSS has been performed using mechanically or neon scrambled footshock (e.g., Miller et al., 1977, Experiments 2-5). Although Biederman and Furedy (1970) argued that only unscrambled footshock permitted overt modification of delivered shock, the same authors (1976) have more recently reported that, even with scrambled footshock of brief duration, rats are able to slightly attenuate the amount of current that passes through them. This could result either from an overt postural modification or from an internal preparatory response that results in a change in the animal's resistance provided the shock is not from a constantcurrent source. Aside from any reduction in total current through the animal, it is also possible that postural modification could attenuate the affective value of the shock by altering the distribution of the current density.

As most of the PSS studies to date have used brief scrambled footshock, it is critical for research attempting to discern the factors controlling PSS that the role of unauthorized modification of brief-duration scrambled footshock be documented. The present study addresses this question.

\section{METHOD}

\section{Subjects}

Twenty-four adult male albino rats (Charles River CD), weighing $330-420 \mathrm{~g}$ at the start of the experiment, were used as subjects. The rats were individually housed in concinuous light and were maintained on ad-lib water and Purina Laboratury Chow. In a lick suppression study more than three weeks earlier, each subject had received one, two, three, or four footshocks of .5 -sec duration. Subjects were counterbalanced across groups for their prior experience. 


\section{Apparatus}

The apparatus were 12 BRS-LVE Model 146-04 twocompartment shuttleboxes, each enclosed in a sound-attenuating chamber. The compartments of the shuttlebox each measured $22.5 \times 20 \times 19.5 \mathrm{~cm}$ and were separated by a divider containing a $5-\mathrm{cm}$ semicircular opening forming a rounded archway. The compartments were made discriminable by vertical black and white stripes on all four walls of each compartment, the stripes being $.3 \mathrm{~cm}$ wide in one compartment and $1.9 \mathrm{~cm}$ wide in the opposite compartment.

Each apparatus was illuminated by an $8-W$ light bulb centered over the intercompartmental partition, and was furnished with a ventilation fan and a $45-0 h m$ speaker for signal delivery. The signal was a $5-\sec 24-\mathrm{Hz}$ click $5 \mathrm{~dB}$ above a $67-\mathrm{dB}$ white noise background. A .7-mA constant-current $60-\mathrm{Hz}$ scrambled footshock of $.5-\mathrm{sec}$ duration could be delivered through the grid floor of the shuttlebox. Each grid of the apparatus could be electrified in respect to every other grid through the use of a neon daisy-chain scrambling circuit. The brevity of the shock was consistent with most of the published studies of PSS and was intended to minimize modification of, or escape from, footshock. All programming equipment was located in a separate room to prevent relay noises from serving as cues.

\section{Procedure}

Subjects were divided into two groups of 12 animals each. The daily session for each group was $11 \mathrm{~h}$ long, beginning for one group at 0930 and for the other group at 2130. All animals were run for 29 consecutive daily sessions. Each session was divided into 1,32030 -sec epochs, with the subjects' position recorded at the beginning of each epoch. Shock was delivered on a random $25 \%$ of the epochs, yielding an average intershock interval of $2 \mathrm{~min}$. If an animal was on Side $A$ of the apparatus at the beginning of a shock epoch, a signal immediately preceded the shock on a random $80 \%$ of the shock epochs and immediately followed the shock on the remaining $20 \%$. If the animal was on Side B of the apparatus at the beginning of the shock epoch, $100 \%$ of the shocks were immediately preceded by the signal. (The 80\%-100\% contingencies had been imposed for reasons that are irrelevant to the present demonstration. The actual study for which they had been designed was discontinued as a result of the findings presented below.) Crossings during a shock epoch had no effect on the signal in progress.

No signals or shocks were presented on Session 1, which was used to adapt the subjects to the apparatus. The locations of Side $\mathbf{A}$ and Side B were counterbalanced across subjects for left and right, wide and narrow stripes, and for the subject's preferred position during the adaptation session.

Each animal was observed during at least two shocks per session in an attempt to detect any subjects avoiding or modifying the footshock. On Session 29 each subject was observed for 20 shock epochs.

\section{RESULTS}

Preference data from the day and night groups were combined for analysis, as no significant difference was found between groups $(p>.10)$. Animals showed a significant preference for Side B, on which $100 \%$ of the shocks were signaled, by Session $4[\mathrm{t}(23)=3.93, \mathrm{p}<$ $.001]$, and this preference continued throughout the remaining sessions.

Although subjects demonstrated a reliable preference for the higher probability of shock being signaled, the daily observations of the animals revealed evidence of avoidance or modification of the footshock through behaviors such as rearing or leaning against the Plexi- glas walls of the apparatus. The frequency of such behaviors was investigated in detail by the multiple observations on Session 29. Postural modifications during the shock were categorized as full rearing when the angle between the floor and the subject's major body axis appeared greater than $45 \mathrm{deg}$, and as partial rearing when the angle was less than $45 \mathrm{deg}$. Each of these two categories was subdivided as to whether the postural modification occurred during or prior to the signal to determine operant levels of such responses. Exclusive of these categories, the number of postural adjustments resulting in avoidance, defined as a complete lack of response to the shock, was recorded.

Postural modification was found for $63.5 \%$ of the shocks observed on Session 29. Of these, $31.8 \%$ involved full rearing, $61.7 \%$ partial rearing, and $6.5 \%$ resulted in complete avoidance. Partial rearing, the most frequent modification, was typically a very subtle response in which the angle between the floor and the subject's major body axis rarely appeared to exceed $5 \mathrm{deg}$. When partially rearing, the animal's forepaws were ordinarily raised approximately a millimeter above the grid, generating a gap so small as to go unnoticed by an observer looking down on the animal, and to be easily overlooked even when the observer was at eye level with the animal.

Full rearing was initiated significantly more often during the signal than prior to signal onset, $28.8 \%$ and $3.0 \%$, respectively $\left[\chi^{2}(1)=19.34, p<.001\right]$; the same was true for partial rearing, $58.7 \%$ and $3.0 \%$, respectively $\left[\chi^{2}(1)=48.58, \mathrm{p}<.001\right]$. Each subject modified at least $20 \%$ of the shocks during which it was observed.

\section{DISCUSSION}

Over the large number of trials animals commonly receive in PSS studies, it is highly likely that they learn to overtly modify and/or avoid scrambled footshock. Each of the 24 subjects in the present study was observed making postural modifications which in some cases apparently resulted in complete avoidance of the shock, as indicated by the absence of a visible reaction. Full rearing was not as frequent as low, partial rearing in which subjects briefly released their front paws from the grids while keeping their torsos close to the floor. These latter postural modifications are not obvious and hence are easily overlooked. The use of apparatus with low ceilings (e.g., Badia, Harsh, Coker, \& Abbott, 1976) does not preclude modification due to forepaw movement.

The frequency with which the observed forepaw modifications occurred prior to shock onset and their failure to habituate suggest that such modifications may reduce the affective value of the shock. Perceived aversiveness of a given shock is related to the total current flow through the subject, the current density, and the anatomical site of the shock. The observed modifications clearly altered the current density and anatomical location of the shock. It is unclear whether these modifications also attenuated the total current flow, although this is unlikely in the present procedure given the use of a constant-current shock source in which 2.5 megohms were in series with each animal. Notably, the current intensity and duration values in this study were identical or quite similar to those of most previous PSS studies using footshock.

The observed modification of current density distribution and probably consequent modification of the affective value of 
the shock does not deny that animals do prefer signaled over unsignaled shock when possibilities for modification are eliminated. As previously mentioned, PSS is a reliable phenomenon in fixed electrode preparations where postural modifications have no effect. The possibility of such modifications does, however, present problems in interpreting PSS data from studies using footshock. Postural modifications such as those observed in the present study constitute an apparent bias toward preparatory responding explanations of PSS. However, such explanations are properly concerned with an internal preparatory response that attenuates the perceived aversiveness of an externally unmodifiable shock. For this reason, the ability of the animal to overtly modify the shock would likely overshadow any evidence for an internal preparatory response. Similar modifications, if present in other PSS studies, should not have created false positive indications of the role of signaled safety, as the signaled safety hypothesis states that the animal is concerned with the presence of safety rather than the aversiveness of the shock. According to a signaled safety analysis, any modification of the shock itself would not directly alter the safety of the intertrial interval except in instances of complete shock avoidance.

If the PSS phenomenon is to be rigorously analyzed and understood, it is imperative that the subject be incapable of overtly modifying the affective value of the shock so as to exclude trivial explanations based on instrumental responding and to allow clear interpretations of experimental findings. Scrambled footshock does not appear to meet this requirement. An alternative method for shock delivery in PSS experimentation is the use of fixed electrode preparations. Fixed electrodes involve certain disadvantages; they are time consuming to apply and generally more expensive to instrument. A more serious drawback which typically has been present with fixed electrode preparations is the potential sampling bias created when subjects which remove the electrodes or severely mutilate themselves must be removed from the study (e.g., Miller et al., 1974). To overcome this problem, we have developed a reliable and inexpensive method for delivering fixed electrode tailshock to freely ambulatory rats in which the animals do not have access to the electrode site and are therefore unable to remove or damage the electrode. Berk, Marlin, and Miller (1977) provide a full description of this system. Due to the modifiability of scrambled footshock, such fixed electrode preparations offer a viable alternative and should be more widely employed in PSS research.

\section{REFERENCES}

Badia, P., \& Culbertson, S. The relative aversiveness of signaled vs. unsignaled escapable and inescapable shock. Journal of the Experimental Analysis of Behavior, 1972, 17, 463-471.

Badia, P., Harsh, J., Coker, C. C., \& Aвbott, B. Choice and the dependability of stimuli that predict shock and safety. Journal of the Experimental Analysis of Behavior, 1976, 26, 95-111.

Berk, A. M., Marlin, N. A., \& Miller, R. R. A system for delivering tailshock to freely ambulatory rats. Physiology and Behavior, 1977, 19, 815-818.

BerLyne, D. E. Conflict, arousal, and curiosity. New York: McGraw-Hill, 1960.

Biederman, G. B., \& Furedy, J. J. Preference-for-signaled-shock phenomena: Signaling shock is reinforcing only if shock is modifiable. Quarterly Journal of Experimental Psychology, 1970, 22, 681-685.

Biederman, G. B., \& Furedy, J. J. Preference for signaled shock in rats? Instrumentation and methodological errors in the archival literature. Psychological Record, 1976, 26, 501-514.

Fisher, C., \& BADiA, P. Preference for signaled or unsignaled shock in goldfish. Bulletin of the Psychonomic Society, 1975, 6, 195-197.

LOCKARD, J. S. Choice of a warning signal or no warning signal in an unavoidable shock situation. Journal of Comparative and Physiological Psychology, 1963, 56, 526-530.

Miller, R. R., Daniel, D., \& Berk, A. M. Successive reversals of a discriminated preference for signaled tailshock. Animal Learning \& Behavior, 1974, 2, 271-274.

Miller, R. R., Marlin, N. A., \& BerK, A. M. Reliability and sources of the preference-for-signaled-shock phenomenon. Animal Learning \& Behavior, 1977, 5, 303-308.

Perkins, C. C., JR. The stimulus conditions which follow learned responses. Psychological Review, 1955, 62, 341-348.

Perkins, C. C., JR. Analysis of the concept of reinforcement. Psychological Review, 1968, 75, 155-172.

Perkins, C. C., Jr., Seymann, R. G., Levis, D. J., \& Spencer, H. R., JR. Factors affecting preference for signal-shock over shock-signal. Journal of Experimental Psychology, 1966, 72, 190-196.

Seligman, M. E. P. Chronic fear produced by unpredictable electric shock. Journal of Comparative and Physiological Psychology, 1968, 66, 402-411.

(Received for publication January 10, 1978.) 